\title{
Electrophysiology of Caudal Neurosecretory Cells in the Skate and Fluke
}

\author{
M. V. L. BENNETT and S. FOX \\ Department of Neurology, College of Physicians and Surgeons, Columbia University; \\ Mental Health Research Institute, University of Michigan; and the \\ Marine Biological Laboratory, Woods Hole
}

Received January 18, 1962

The caudal neurosecretory cells of two species of skate (Raja erinacea and $R$. ocellata) and of the fluke (Paralichthys dentatus) were studied by intracellular microelectrode techniques. The cells were capable of producing spikes and of being synaptically activated.

The neurosecretory cells of the skate were intermingled with other neurons within the spinal cord and could not be penetrated under visual control. IIowever, a class of responses was recorded that were readily distinguishable from those of motoneurons and myelinated fibers and which very likely came from the much larger neurosecretory cells. The spikes were longer in duration and had pronounced undershoots. Nearby stimulation on the surface of the cord activated the cell bodies directly rather than evoking antidromic spikes. Brief stimuli, intra- or extracellular, could produce direst spikes of very long latency, thus indicating a low degree of accommodation. The presynaptic pathway was slowly conducting and of high threshold.

The neurosecretory cells of the fluke were anatomically isolated from other cell bodies, but recordings from axons and somata had to be distinguished electrophysiologically. Recordings from cell bodies were characterized by the occurrence of postsynaptic potentials, which could be adequate to initiate spikes. The spikes were rather long in duration and usually followed by an undershoot. Those in response to antidromic stimulation had an inflection on the rising phase caused by delay of propagation at the axon hillock. Invasion of the soma could be blocked by hyperpolarization or refractoriness, leaving the axonal component of the spike. The threshold in the initial part of the axon was not significantly lower than in the soma. There was little accommodation, as indicated by the long latencies of responses to brief threshold stimuli.

The antidromic responses in a cell often had several distinct latencies when stimulation was over the urohypophysis. The properties of the longer latency responscs suggested that thcy were initiated in the terminals of the axons and that the delay resulted from very slow propagation in these structures. Antidromic conduction could be blocked in the axon at points some distance from the soma as well as at the axon hillock.

Spikes recorded from the neurosecretory axons were similar in duration to those from the cell bodies. They were characterized by the occurrence either of synaptically evoked spikes without recording of p.s.p.'s adequate to iniate them or of direct responses to stimulation on each side of the recording site. Hyperpolarization could cause block of propagation along the axon which was associated with block of a later component of the recorded spike.

The presynaptic pathway ran anteriorly to the neurosecretory cells. Its conduction velocity suggested that it consisted of small myelinated fibers. The individual presynaptic fibers appeared to innervate both rostral and caudal cells. Intravenous injections of hypotonic solutions could cause sufficient activity in the presynaptic fibers to initiate impulses in the neurosecretory cells. 


\section{INTRODUCTION}

The structures of the caudal neurosecretory systems of fish have long been known and, indeed, their neurons were the first suggested to be secretory in function (Speidel, 1919, 1922). However, little attention was paid to these interesting systems until the recent studies of Enami (1959) whose work has resulted in a revival of interest in problems both of structure and function. The anatomical relations in the various groups are reviewed in this journal by Bern and Takasugi (1962).

The present investigations were undertaken in the hope that the caudal neurosecretory systems would provide insight into the role of electrical activity in neurosecretion. Also, any electrophysiological specializations associated with secretory function would be of general interest. Without reviewing these questions in detail it may be noted that many workers, starting with Speidel (1919), have anatomically demonstrated an electrically induced depletion of neurosecretory material. More recently Harris (1947) and now Cooke (1962) found release of hormones into blood or perfusion fluid following electrical stimulation. Potter and Loewenstein (1955) showed propagated action potentials in a neurosecretory tract, and Cross and Green (1959) recorded activity of presumed neurosecretory cells on physiological stimulation. However, in each of these instances neurons other than specifically neurosecretory ones may have been responsible for the observed sensitivity to electrical stimulation or for the recorded electrical activity (cf. Bern, 1962). Probably the first definite demonstration of electrical activity in neurosecretory cells was reported by Morita et al. (1961) in a note that appeared while this study was in progress. In the caudal neurosecretory cells of the eel, Anguilla japonica, these workers found spike responses and synaptic activation with very nearly the same properties as are reported here for the skate.

Two criteria may be set up to establish a causative role of electrical activity in neurosecretion. Firstly, the neurosecretory cells should become electrically active when the animal is stimulated physiologically to seerete the neurohormone. Secondly, electrical activity of the neurosecretory cells alone should result in secretion. The data presented here amply demonstrate that the electrical behavior of the caudal neurosecretory cells is similar to that of the motoneurons from which they are presumably derived. Although the precise nature of the physiological stimulus is unclear, it appeared possible to evoke electrical activity of the cells by essentially physiological stimulation. However, no measure was made of actual secretion.

\section{METHODS}

The fluke, Paralichthys dentatus, and two skates, Raja erinacea and $R$. ocellata were used Differentiation of the skate species, which may require counting of rows of teeth, was not alwavs made. However, species differences were not noted between definitely identified individuals.

The animals were immobilized by intravenous injections of D-tubocurarine (ca. $10 \mathrm{mg} / \mathrm{kg}$ ). In the skates the spinal cord was exposed in the region of the dorsal fin from either the dorsal or ventral side, the former approach being rather more satisfactory. A small exposure for stimulation was sometimes made several centimeters rostrally. In the fluke the urohypophysis and a short length of spinal cord were exposed from the left side, the animal lying on its right. its normal position.

Glass capillary microelectrodes filled with $3 \mathrm{M}$ $\mathrm{KCl}$ were used for recording. Rectangular pulse stimulation through the recording electrode was carried out with a bridge eircuit similar to that of Araki and Otani (1955) and Frank and Fuortes (1955). Stimulating currents were always monitored on one oscilloscope trace although for simplicity this trace is omitted from most of the figures. Superimposed records were often made at one or several stimulus strengths. In all figures positivity of the recording electrode is shown as an upward deflection. In the current monitoring traces, an upward deflection indicates a depolarizing current.

The bridge method of stimulation involves uncertainty is to the potential during stimulating pulses, since the electrode resistance may change as a result of the current flow. However, the cells being of high resistance the currents used were always small. Where inferences were to be made from the absolute potential level, only those cases where the bridge was in balance at the beginning and end of the pulse were considered. 
Sometimes small hyperpolarizing currents were used to prevent spontaneous firing or to enlarge a response (cf. Fig. 4E).

The DC potential of the electrode usually showed large negative changes as it was pushed through the cord. Many of these potentials were not associated with neurons as they were unchanged by relatively large movements, and no activity could be evoked by stimulation. A considerable uncertainty was thus introduced into the measurement of DC level, and no attempt was made accurately to measure neuronal resting potentials, although they were undoubtedly inside-negative in the usual range. Paired $125 \mu$ silver electrodes insulated except at the tips were used for bipolar surface stimulation of the cord and urohypophysis.

\section{RESULTS}

\section{The Caudal Neurosecretory System IN THE SKate}

The caudal neurosecretory cells in the skate lie in the posterior spinal cord, clustering at the level of the rostral margin of the dorsal fin and extending caudally to near the end of the cord and several fin lengths rostrally (Speidel, 1919). They are interspersed among the motoneurons and interneurons, and have at most short unmyelinated axons which descend to the ventromedial part of the cord. Their cell bodies were 50 to $100 \mu$ in diameter in the animals used in this study, considerably larger than the adjacent neurons, but not the extraordinarily large size reported by Speidel. They are not visible externally owing to the high refractivity of the myelinated fibers in the surrounding nerve tissue, and identification of recordings from them was by inference from electrophysiological data. Three types of intracellular recordings were found. The first was similar to that which has been recorded from other cell bodies in the vertebrate central nervous system and the second to that from myelinated fibers (cf. Eccles, 1957; Frank and Fuortes, 1955). The third was distinctively different and presumably came from the neurosecretory cells. The first two will be described in some detail in order to emphasize their differentiation from the responses of the neurosecretory cells. This data is also useful for comparison to that from the ncurosecretory cells of the fluke which for anatomical reasons had a number of electrophysiological similarities.

Responses of Ordinary Neuron Somata. The responses in nonneurosecretory cell bodies were distinguished from those of fibers mainly by the occurrence of postsynaptic potentials (p.s.p.'s). Most cell bodies encountered were probably of motoneurons, but the method of stimulation of the cord surface rather than of ventral roots or peripheral nerve did not allow positive identification. With respect to a motoneuron, cord stimulation with eaudally placed electrodes could produce a mixed volley containing both antidromic and synaptic components. A rostral stimulus could involve only synaptic activation.

The mixed stimulating effect of a caudit stimulus on a presumed motoneuron is shown in Fig. 1. To weak stimuli the cell showed a graded p.s.p. after a delay of

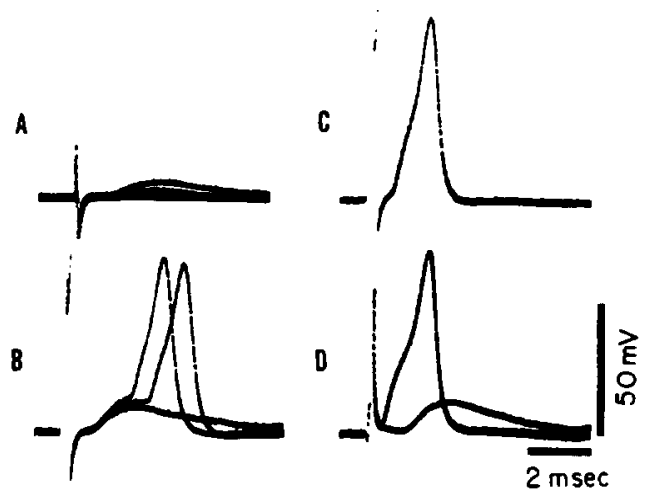

Fia. 1. Responses in a presumed motoneuron. Stimulation caudal to the recording site; of one polarity and increasing strength in $\mathrm{A}-\mathrm{C}$, of opposite polarity and constant strength in D. Several superimposed traces in $A, B$, and D. A : Weak stimulation produced a graded subthreshold p.s.p. B: The p.s.p. became adequate to evoke a spike. C: An antidromic spike was evoked so that little p.s.p. could be seen. D: Reversed polarity of stimulation at a strength which occasionally evoked an antidromic spike. The p.s.p. which occurred when the antidromic spike did not was inadequate to excite the cell. Note the inflection on the rising phases of both synaptic and antidromic spikes denoting delay of propagation from initial segment to soma. 
about 1 msee (A). On progressively stronger stimulation the p.s.p. became adequate to evoke a spike, about 2 msec in duration, which then decreased in latency (B). Still stronger stimulation produced an antidromic spike with a shorter latency than the p.s.p. (C). Little contribution from the p.s.p. was then seen, presumably because of short circuiting by large conductance changes involved in spike generation (Eccles, 1957; Grundfest, 1959). On increasing the strength of stimuli of opposite polarity, the threshold for an antidromic response was reached before a p.s.p. was evoked that was large enough to initiate a spike (D). In other experiments using both rostral and caudal stimulation, cells of this type were found to respond only synaptically to rostral stimulation (cf. Fig. 3A).

The antidromic spikes had marked inflections on their rising phases and by stimulating in the relative refractory period (Fig. 2) or during hyperpolarization applied through the recording electrode, the spikes could be separated into two components at this point. The first component can be ascribed to activity of the initial segment of the axon and the second to that of the soma-dendrite membrane (cf. Eccles, 1957; Fuortes et al., 1957), the inflection

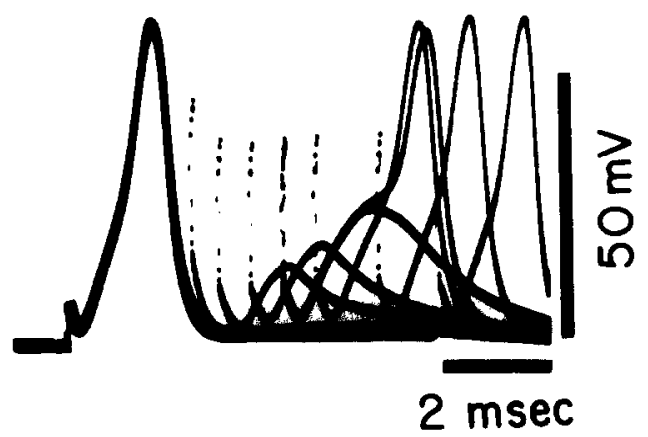

FIG. 2. Failure of antidromic invasion in the refractory period. Stimulation just caudal to the recording site. Superimposed traces of paired stimuli at different intervals. At progressively shorter intervals the second spike component ascribable to the soma membrane became delayed and then failed. The remaining potential, the initial segment response, became reduced at still shorter intervals. and failure of invasion of the soma being due to a reduction in safety factor for propagation at the axon hillock region. The reduced safety factor would probably have been not only a result of enlargement of the membrane, but also of increased threshold in the soma. This property is indicated since synaplically evoked spikes also had inflections on their rising phases (Fig. 1B). Apparently impulses arose in the initial segment region, which would thus have to have been of lower threshold, and propagated back into the soma as well as out the axon. This pattern of impulse initiation has been demonstrated in cat motoneurons (Fuortes et al., 1957; Coombs et $a l ., 1957$ ) and probably also occurs in those of the toad (Araki and Otani, 1955) and of the puffer (Bennett, unpublished).

Responses in Myelinated Fibers. Either of two properties served to identify the responses ascribable to myelinated fibers. Spikes which were synaptically activated as indicated by long and variable latency occurred without the recording of a p.s.p. adequate to initiate them (cf. Frank and Fuortes, 1955). Alternatively, spikes could be evoked directly, i.e., with short and constant latency, by stimulation on either side of the recording electrode. The second criterion might also be satisfied by responses in the soma of a bipolar neuron, but cells of this kind probably did not occur in the spinal cord. A fiber having the first property is shown in Fig. 3. To caudal stimula-

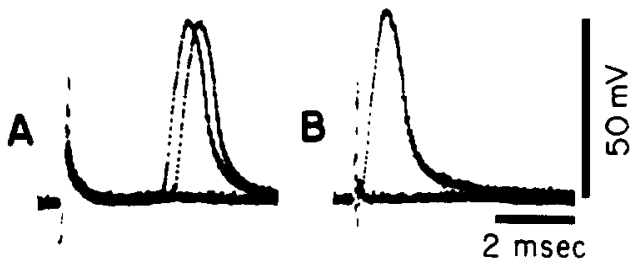

FIg. 3. Responses of a presumed motoneuron fiber. Several superimposed traces in each record A : Stimulation a few millimeters rostral to the recording site. The spike had a long and variable latency and was therefore due to synaptic activation of the neuron. No p s.p.'s were seen, however. B: Short latency and therefore direct responses of the axon to threshold stimulation a few millimeters caudal. 
tion a very short latency response was produced (B), but rostral stimulation elicited only a much longer and variable latency response without the recording of a postsynaptic potential (A). A fiber having the second property is shown in Fig. 4. Both rostral and caudal stimulation produced responses of constant latency less than 0.3 msec. It could be inferred from the distance between the stimulation sites that the fiber belonged to a spinal tract rather than to a motoneuron.

The time course of fiber responses was often distinctive from that of soma responses. The spikes were usually briefer

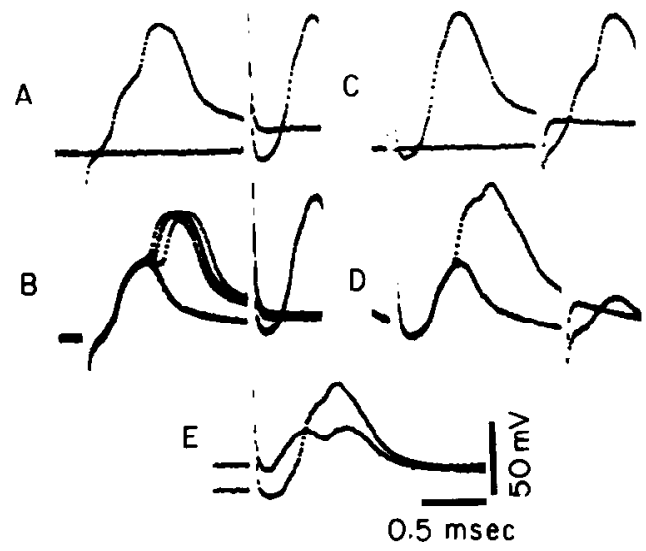

FIG. 4. Responses of a presumed spinal tract fiber. Stimulation $3 \mathrm{~mm}$ rostral and $2 \mathrm{~mm}$ caudal. Since the fiber was injured by penetration, a small hyperpolarizing current was applied intracellularly to maintain spike height. A: The response to the rostral stimulus left the fiber refractory to the caudal stimulus (superimposed traces with and without rostral stimulus). Both responses had an inflection on the rising phase. B: Stimulation as in $\mathbf{A}$, but with increased hyperpolarization sufficient so that the second component of the rostral response was sometimes blocked. When this component failed the fiber was no longer refractory to the caudal stimulus (superposition of traces where second component did and did not occur). C: As in A, but reversed order of stimulation. D: As in B, but reversed order of stimulation. The response to caudal stimulation showed a second inflection near the peak. The response to rostral stimulation was small, and probably involved only its first component seen in $\mathrm{B}$, the hyperpolarization being greater. E: Superimposed traces showing reduction in the response height on removal of the hyperpolarizing current although there was some overlap in duration. In fibers apparently in good condition the rising phase was somewhat faster than the falling phase and usually had little sign of an inflection. Spikes in more deteriorated fibers, however, could have marked inflections (Fig. 4), and even in the best fibers hyperpolarization or refractoriness might produce fractionation into two components which could resemble those recorded in cell bodies. When hyperpolarization caused the second component to fail, propagation along the fiber was blocked (Figs. 4B, 4D). The two components were probably due to successive nodes of Ranvier, as has been directly demonstrated in peripheral fibers (Tasaki, 1952). An additional inflection was sometimes seen in fiber responses as near the peak of the spike in Fig. 4D. This complication was probably due to activity of another node farther along the fiber.

Responses of Neurosecretory Cells. The spike responses ascribable to the neurosecretory cells were different in a number of respects. Most obviously they were 4 to 10 msec in duration, significantly longer than the other responses, and they were usually followed by a large and long-lasting undershoot of the resting potential (Fig. 5A).

Spikes evoked in the neurosecretory cells by intracellularly applied depolarizing currents were of shorter latency with stronger stimuli (Fig. 5B). Following a brief threshold pulse the latency could be very long with the membrane potential hovering more or less constant for some time before either slowly rising to produce a spike or slowly falling back to the resting level $(\mathrm{C}, \mathrm{D})$. The magnitude of the undershoot was probably partly due to depolarization from injury of the cell by the microelectrode. since most of the cells were rhythmically active when initially penetrated, but often ceased this firing with no diminution in the height of an evoked spike.

$\Lambda$ s well as in spikc duration and undershoot the neurosecretory cells were distinet in their response to external stimulation. Directly evoked spikes could be oblained only with nearby stimulation and, moreover, appeared to be initiated in the cell 
body rather than in the axon. Typical externally croked responses are shown in Fig. 6A. Very long latency spikes occurred with threshold stimulation, but rather than arising from the baseline they were initiated by a depolarization which was continuous with the stimulus artifact. The spikes arose from the same level of depolarization as required for intracellular stimulation $(\mathrm{C})$. These properties were not

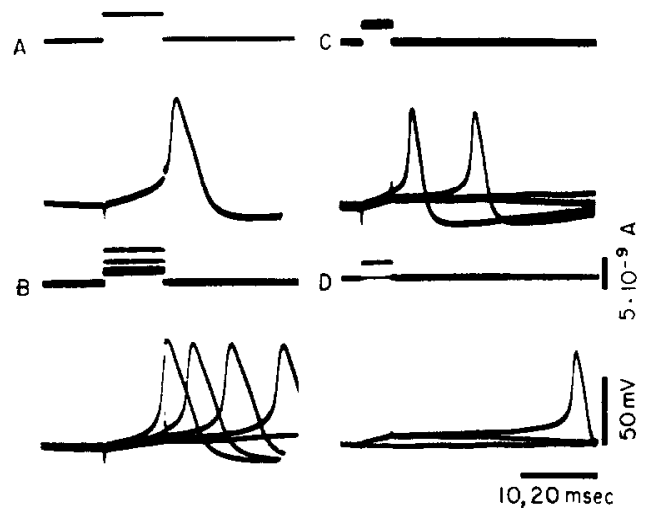

FIG. 5. Intracellular stimulation of a neurosecretory cell. Upper trace, applied current; lower trace, intracellular potential. A: Spike response to suprathreshold stimulation showing long duration and ensuing undershoot of the potential with respect to the resting value. B: Superimposed responses to stimuli of varying strength, the shorter latency responses being evoked by the stronger stimuli. C, D: Superimposed responses to brief threshold stimuli, recorded at half the sweep speed. The responses could have very long latencies.

affected by reversing the polarity of the external stimulus (B). Unlike antidromic responses there were no inflections on the rising phase.

The neurosecretory cells could also be activated synaptically as shown in Fig. 7 . The presynaptic pathway was of high threshold and probably also had a low conduction velocity since even with relatively nearby stimulation the p.s.p.'s had a long latency. The recording in B had a large component of subthreshold response, since a small hyperpolarization greatly reduced the amplitude (C), and the remaining potential had an early peak.
The Cacdal Neurosecretory Sisted IN THE FluKe

The caudal neurosecretory cells of the fluke lic in the last few segments of the vertebral canal. At least in the more posterior regions motoneurons are absent, and the cell bodies present a pure population. Their unmyelinated axons pass posteriorly to terminate in a highly vascularized

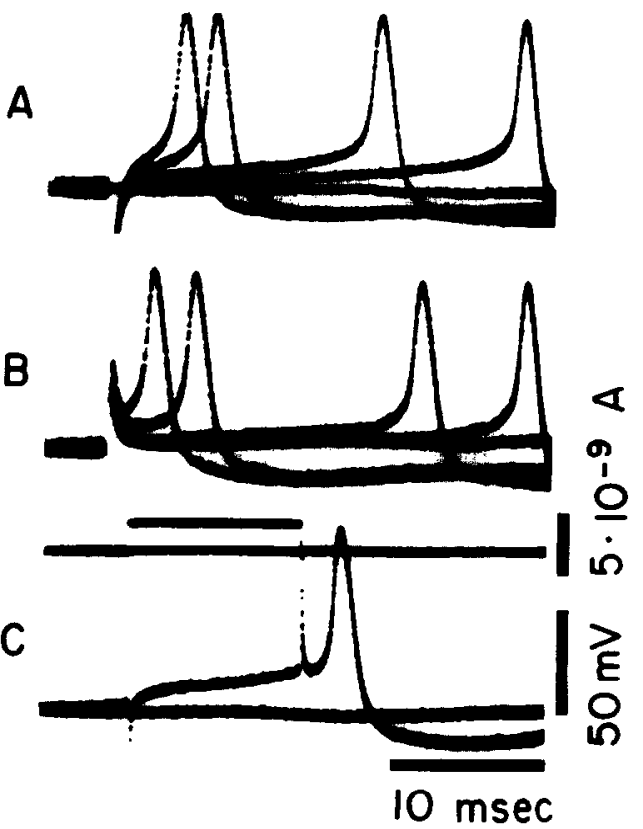

FIG. 6. External stimulation of a neurosecretory cell. Very long latency responses could be produced by brief stimuli applied nearby to the surface of the spinal cord and with either direction of current through the bipolar electrodes (superimposed traces varying the stimulus strength, of opposite polarity in $\mathrm{A}$ and $\mathrm{B}$ ). The spikes arose from depolarization following the stimulus artifact rather than from the baseline. The level at which they arose was the same as that with intracellular stimulation (C, current in upper trace).

body attached to the ventral side of the cord. This body, the urohypophysis, occupies a small cavity in the last vertebrum (cf. Bern and Takasugi, 1962). In the animals used in this study the cell bodies were 30 to $50 \mu$ in diameter and their axons up to $3 \mu$. In sectioned preparations there was a marked differentiation where the axons entered the urohypophysis. 
In vivo the urohypophysis was, except for scattered pigment cells, opaque white, presumably because of accumulation of neurosecretory product. In the caudal portion the spinal cord was relatively transparent, myelinated fibers being rare, and the neurosecretory cell bodies could be seen within it. However, microelectrode tips were not as readily visible and could not be localized to within the dimensions of a cell body. As discussed with respect to the neurons in the

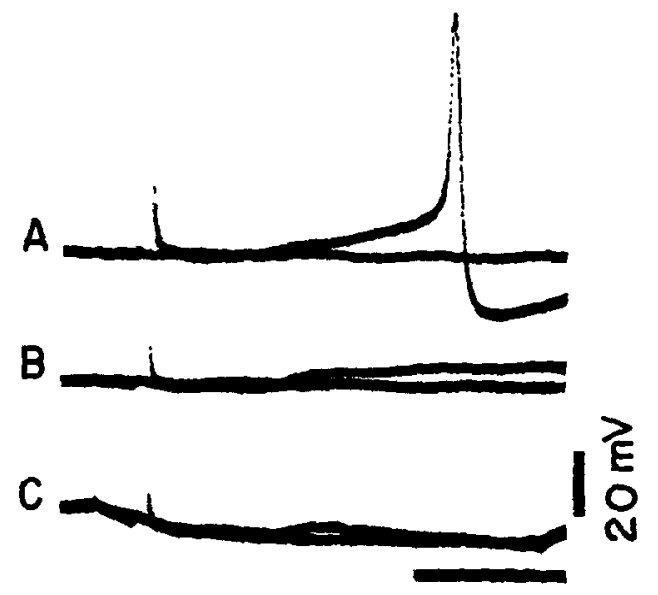

$20 \mathrm{msec}$

Fia. 7. Synaptic activation of a neurosecretory cell. Stimulation about $5 \mathrm{~mm}$ rostral to the recording site. A: A synaptically evoked spike. B: Probably a subthreshold p.s.p. although a spike may have occurred after the end of the oscilloscope sweep. C: A response like that in $\mathrm{B}$ became greatly reduced during a hyperpolarizing pulse and had an early peak. These changes indicate that the p.s.p. in B had evoked a large subthreshold response.

skate, electrophysiological properties serve to distinguish responses in cell bodies from those in axons.

Neurosecretory Tract Responses. When stimuli were given through electrodes placed over the urohypophysis and the spinal cord a few millimeters away was penetrated by a microelectrode, an initially positive triphasic response was recorded throughout the cord (Fig. 8A). A similar potential was recorded when stimulation was rostral to the electrode (Figs. $8 \mathrm{~B}, 8 \mathrm{C}$ ). These responses were localized to the pos- terior of the cord and were graded with stimulus strength. They represented chiefly summation of conducted action potentials in axons of the neurosecretory tract. The conduction velocity was about $1 \mathrm{~m} / \mathrm{sec}$ in this experiment (dotted line in Fig. 8) but was often somewhat slower. When the electrode was inside a cell, the tract response could still be recorded, and the cell's activity appeared superimposed upon it.

Responses in the Neurosecretory Cell

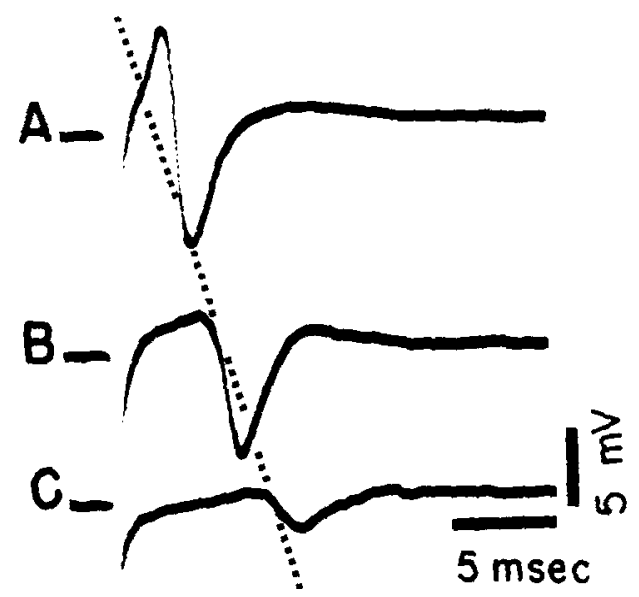

FIG. 8. Tract responses of the neurosecretory axons. A: Triphasic response to stimulation over the urohypophysis $2.5 \mathrm{~mm}$ caudal to the recording site. B, C: Responses to stimulation of the cord 5.5 and $7.5 \mathrm{~mm}$ rostral to the recording site. The distances between the records A-C are proportional to the distances of the stimulating electrodes from the recording site. The dotted line shows on the same scale the latency of an activity conducted at $1 \mathrm{~m} / \mathrm{sec}$.

Bodies. Spike responses were recorded from cell bodies which on anatomical grounds could only have been those of the neurosecretory cells. As with ordinary neurons in the skate, cell body responses were identified by the occurrence of graded p.s.p.'s which could usually be made adequate to initiate a spike (Fig. 9A). The cell bodies also gave typical antidromic spikes in response to stimuli caudal to the recording site. An antidromic spike was usually preceded by a potential due to the neurosecretory tract response and had an inflection on its rising phase $(\mathrm{C})$. The inflection pre- 

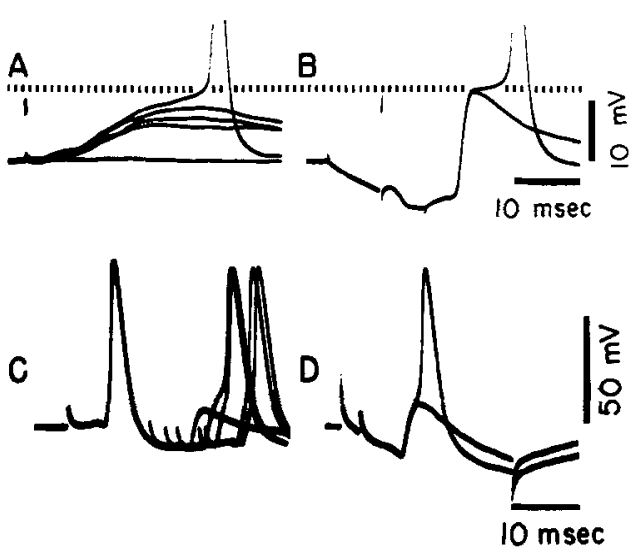

FIG, 9. Synaptic and antidromic spikes in the neurosecretory cell body. A, B and C, D: Two different cells. Stimulation rostral to the recording site in $A$, over the urohypophysis in B-D. The antidromic responses in $B-D$ were preceded by a small potential due to the tract response. A: Graded p.s.p.'s in response to graded rostral stimulation showing initiation of a spike at the level of the dotted line (superimposed traces). B: Constant hyperpolarizing pulses were applied intracellularly just adequate to cause occasional failure of antidromic invasion. The hyperpolalizing pulses ended between the stimulus artifact from the caudal electrodes and the beginning of the antidromic response. When the second or soma component failed, the axonal component remained (superimposed traces with and without invasion). The potential at which the soma component arose was close to that for synaptic activation (dotted line). $\mathrm{C}$ : The first antidromic spike had only a slight inflection. When a second antidromic spike was evoked in the refractory period of the first at progressively shorter intervals, the inflection become more pronounced and then the soma component failed, learing the axonal component (superimposed traces). D: In the same cell, demonstration of axonal and soma components by hyperpolarization (superimposed traces with and without invasion).

sumably resulted from delayed propagation at the axon hillock region. By stimulation in the refractory period (C) or during a hyperpolarizing pulse applied through the recording electrode $(B, D)$, the second or soma component could be made to fail, leaving only the response due to the initial part of the axon. The spikes wcre about 5 msec in duration, similar to those of the neurosecretory cells in the skate. Generally they were followed by a prolonged undershoot, but, as this characteristic was not present in all cells, its occurrence may have been a result of injury.

As discussed with respect to the skate. the initial segment in motoneurons appears to have a lower threshold than the soma membrane (Coombs et al. 1957; Fuortes et al., 1957). In the neurosecretory cell of the fluke, however, the initial part of the axon was little, if any, more excitable than the soma. This property may be inferred from Figs. 9A and 9B, where the level at which a synaptically evoked spike arose was very close to that at which the soma component of the antidromic spike arose from the axonal component. If the threshold of the axon had been lower, the synaptically evoked spike would have started from a lower level than the soma component of the antidromic spike. Thus, the delay of antidromic invasion at the axon hillock was solely a result of the enlargement, as was originally thought true of the motoneuron (Eccles, 1957).

Further details of the excitation process are seen in Fig. 10 where tha levels for direct and synaptic activation and for antidromic invasion are compared. With a brief threshold depolarizing pulse the latencies were very long, and two firing levels could be defined, the level where the rising phase became rapid and the somewhat lower level from which the potential either rose slowly to fire, or fell slowly back to the resting level ( $A$, dotted lines). The same course of excitation could be seen with synaptic stimulation (B), the potential continuing to rise slowly before the rapid phase began well after the peak of the p.s.p. (D, arrow).

When antidromic invasion occurred during a hyperpolarizing pulse, no slow rising phase and little delay could be produced with even the most careful adjustment of pulse strength. The level where the rapid rise began was, however, the same as that with synaptic and direct excitation. The absence of a slow rising phase and long delay were a result of the hypcrpolarizing current continuing beyond the peak of the axonal component; the current during this 
time made the membrane very unstable in the threshold potential region. When the hyperpolarizing pulse ended before the peak of the axonal component, a considerably longer delay of antidromic invasion was possible (Fig. 11B). A slow rising phase could then be seen preceding the rapid rise, although here somewhat obscured by the second stimulus artifact. The delays were readily made so long that an impulse after invading the soma propa- dicated by Antidromic Stimulation. The responses of the neurosecretory cells to antidromic stimulation often had the unusual property that they could have quite variable latencies. While the responses to strong stimulation had latencies corresponding to the conduction velocity of the tract response (Fig. 8), weak stimulation often resulted in latencies 10 or even 20 msec longer. The longer latency responses had a number of characteristics indicating

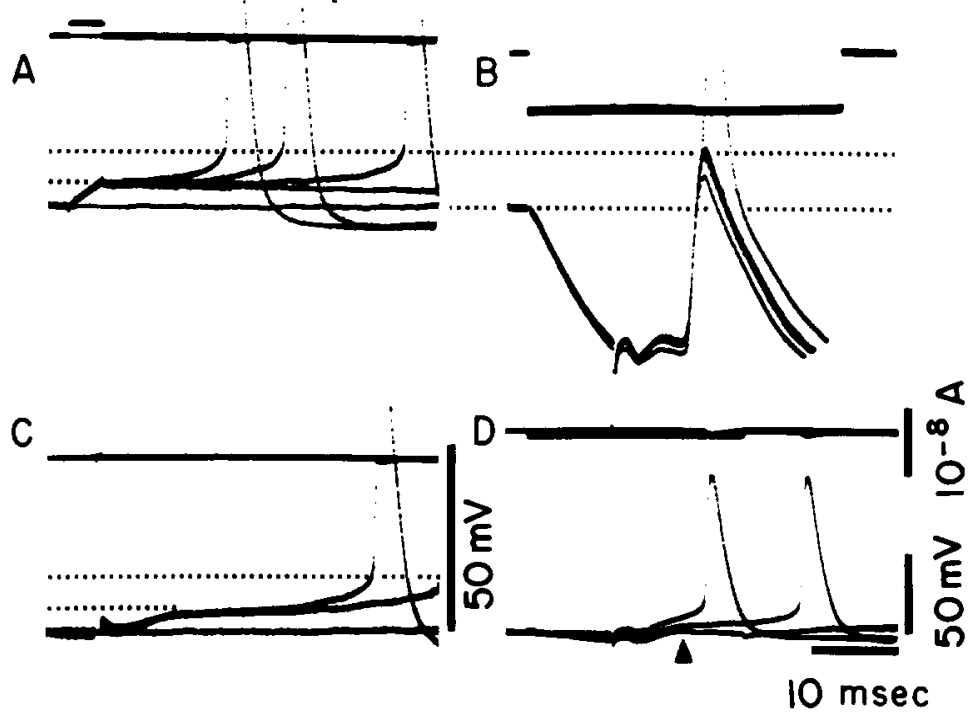

Fig. 10. Excitation of the cell body by different modes. Upper trace, intracellular polarizing current; lower trace, intracellular potential. Several superimposed traces in each record. A: Direct stimulation by a brief threshold pulse. The potential could remain at the level at the end of the pulse and then rise or fall slowly. The rise became rapid at the level of the upper dotted line. B: Synaptic activation, stimulation $4 \mathrm{~mm}$ rostrally. The rapidly rising part of the spike began at the same level as for direct stimulation. The preceding slowly rising phase continued well after the peak of the p.s.p. as shown in D (arrow). C: When an antidromic spike was evoked during a hyperpolarizing pulse, little delay of invasion could be obtained. The potential either rose rapidly or fell from the level where the rapid rise began on direct and synaptic activation. D: Increasing hyperpolarization delayed, then blocked, the synaptic spike showing the early peak of the p.s.p. (arrow, recorded at lower gain).

gated back out the axon, as seen by its block of a second antidromic spike. It was less easy, however, to produce delays than it was with direct or synaptic stimulation. Probably there was active repolarization during the falling phase of the axonal component of the spike which tended, like hyperpolarization, to make the membrane potential of the soma more unstable.

Properties of the Axon Terminals as In- that they were initiated at some site in the axon terminals in or near the urohypoph$y$ sis and that the delay was due to very slow conduction velocity in these structures. They could not be evoked by stimulation rostral to the urohypophysis and were distinct from the synaptically evoked spikes, also of long latency, in that they were not associated with postsynaptic potentials in the cell bodies. 
The antidromic latency in a cell usually assumed several more or less discrete values between which it jumped in an all-ornone fashion, suggesting several different sites of impulse initiation. In Fig. 12A are shown a cell's responses to varying the antidromic stimulus strength near and somewhat above threshold; the latencies clustered around two values. In Figs. 12B$12 \mathrm{D}$ the duration of the stimulus was increased so that the height of the stimulus artifact could be used as a measure of stimulus strength. On a slight increase over

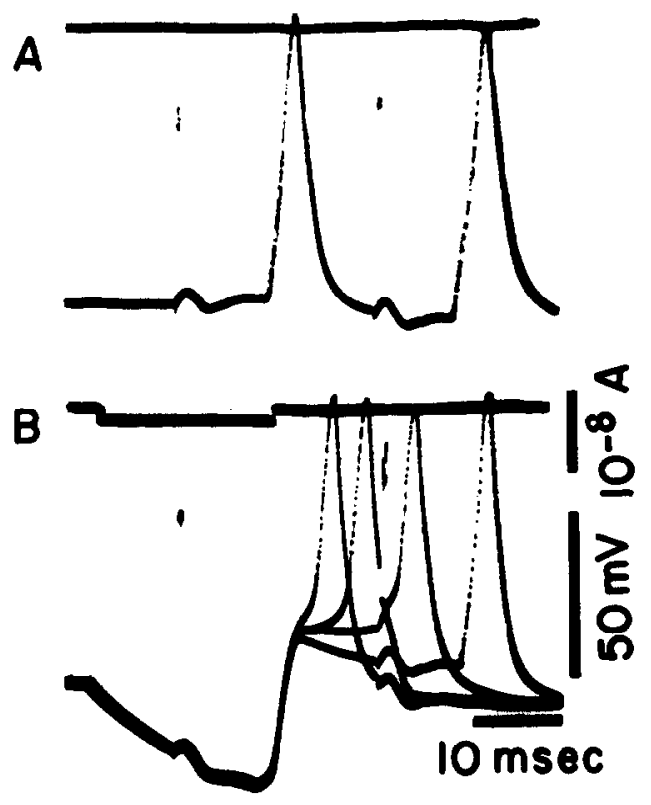

FIa. 11. Delay of antidromic invasion by a preceding hyperpolarizing pulse. Paired stimuli given over the urohypophysis $1.5 \mathrm{~mm}$ caudal to the recording site. Upper trace, intracellular polarizing current; lower trace, intracellular potential. A: With no hyperpolarizing current antidromic spikes occurred in response to both stimuli. B: Constant hyperpolarizing pulses were given which ended on the rising phase of the axonal component of the first antidromic response and which occasionally blocked invasion of the soma (four superimposed traces). When invasion failed, a second antidromic response was obtained (one trace). When invasion occurred (three traces), the delay was sufficient to allow a second impulse to propagate back out the axon as indicated by block of the second antidromic response. With the longer delays a slow rise preceded the rapid rising phase of the soma component. threshold (B), the latency decreised slightly and then jumped to a smaller valuc (C). At the strength in $\mathrm{C}$ the latency could be either long or short. A much greater increase in the stimulus produced a further gradual shortening of latency and then a second but smaller all-or-none jump (D). Between $A$ and $B$ the cell began to deteriorate markedly and a constant hyperpolarizing current was applied to maintain the spike height. The antidromic latencies in $\mathrm{B}$ and $\mathrm{C}$, however, were identical to those in A. As might be expected with external stimulation, reversal of stimulus polarity usually altered the latencies that the antidromic responses could assume.

The results of paired antidromic stimulation were also consistent with the hypothesis of impulse initiation at several distinct sites. The refractory period for initiation of a second antidromic impulse was usually shorter than the interval at which invasion of the soma failed, but the occurrence of the axonal component of the spike was adequate to establish that a second impulse had been evoked (cf. Fig. 9C). In a typical experiment the refractory period was only slightly greater with paired weak stimuli of the strength producing long latency responses than it was with paired stronger stimuli of strength adequate to produce short latency responses (Figs. 13B, 13G). Usually there was very little increase in latency just beforc the second response failed $(G)$, but sometimes the latency to a second strong stimulus could have either the short or the long value $(B, C)$. When a second weak stimulus was given at a somewhat greater interval than the refractory period, the latency in many cells jumped to the value for the stronger stimulus ( $\mathrm{E}, \mathrm{F}$ ) indicating a supernormal period in the part of the axon where the short latency response arosc.

The question may be raised as to whether the long antidromic latencies were due to slow uniform conduction or to delays at low safety factor regions, such as might occur at branch points in the terminals. This problem was investigated by observing the effect of a spike initiated 

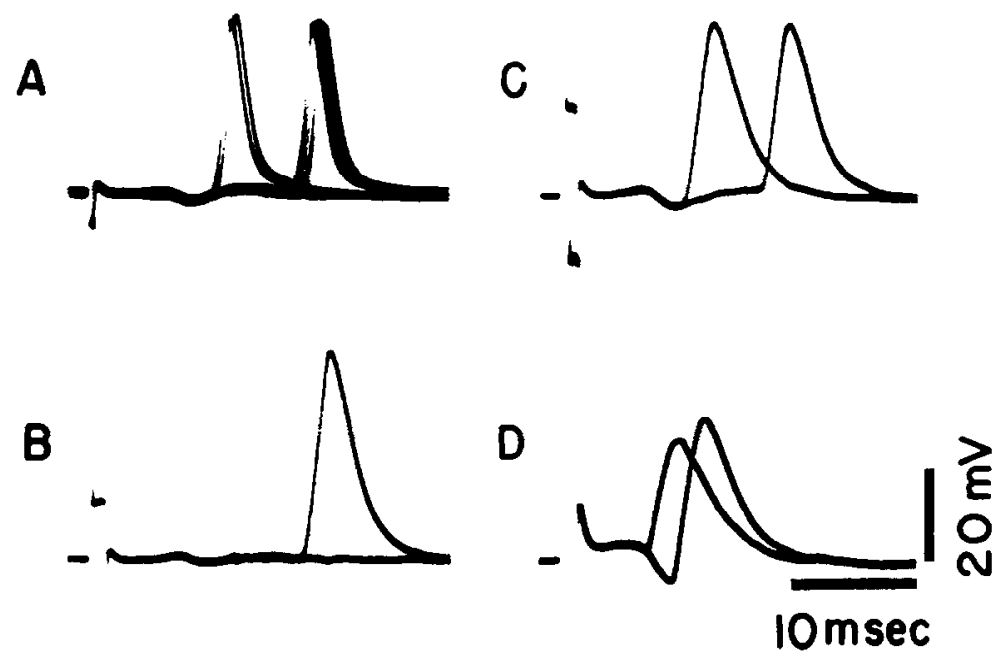

Fig. 12. Effect of stimulus strength on antidromic latency. Stimulation over the urohypophysis about $4 \mathrm{~mm}$ caudal to the recording site. A: Superimposed traces of responses to stimulation at, and just above, threshold. The latencies clustered around two values. B-D: The stimulus duration was lengthened so that the height of the shock artifact could serve as a monitor of stimulus strength (two superimposed traces at nearly constant stimulus strength in each record). Between $A$ and $B$ about 10 minutes had passed in testing other properties of the cell. Shortly before B the cell began to deteriorate and these changes continued during the determination of the thresholds in $\mathrm{C}$ and $\mathrm{D}$. $\mathrm{Hy}-$ perpolarizing current was applied to maintain the spike height. At the stimulus strength in $\mathrm{C}$ the response could have either of two latencies; the longer was slightly shorter than the threshold latency shown in B. At the much greater strength in $\mathrm{D}$, the response could also have two latencies, the longer being about the same as the shorter in $\mathrm{C}$. In spite of the elapsed time and deterioration of the cell the antidromic latencies in $\mathrm{B}$ and $\mathrm{C}$ were identical to those in $\mathrm{A}$.

directly in the soma on a succeeding antidromic response. The response to an antidromic stimulus should be blocked following a direct spike for an interval equal to the time required for the impulse to reach the site of antidromic stimulation plus the refractory period at that site. The refractory period should be equal to that for paired antidromic stimulation and subtracting should give the orthodromic conduction time. If the orthodromic conduction time were equal to the antidromic, it would be likely that the conduction velocity were equal and uniform in the two directions. In fact, in most instances the blocking period of a dircet spikc on a succeeding antidromic response was near or slightly less than the sum of the antidromic conduction time and the refractory period for paired antidromic stimulation, implying near equality of the conduction times (Figs. 13D, 13H). Thus, the long latency appeared to be mainly due to a slow conduction velocity. In the few in- stances where the blocking time was significantly shorter than calculated, the antidromic impulse probably was delayed at some point of low safety factor along the axon. The existence of such points is discussed in the next section.

While the length of the terminals is unknown, the width of the urohypophysis $(0.5 \mathrm{~mm})$ may be taken as an approximation. A conduction time in the terminals of 10 msec thus indicates a conduction velocity of the order of $0.05 \mathrm{~m} / \mathrm{sec}$.

Block of Antidromic Responses Distal to the Axon Hillock Region. In the cat motoneuron, block of the initial segment component of the antidromic spike can be achieved either by stimulating in the refractory period or by hyperpolarizing, propagation failing to occur across the first internode (Eccles, 1957). Although the neurosecretory axons are unmyelinated, electrophysiologically they present points of reduced safety factor distal to the axon hillock region, and hyperpolarization 


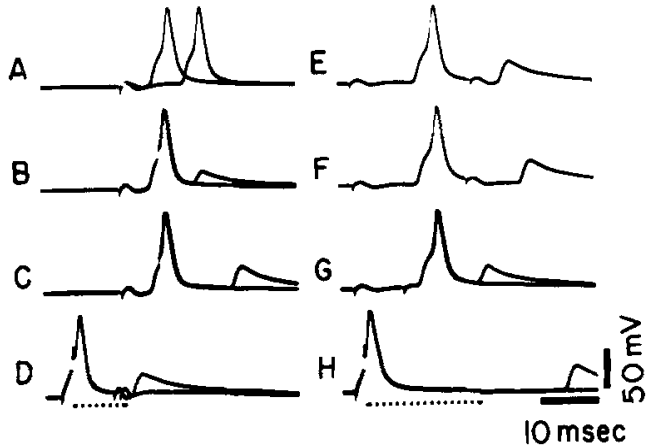

Fig. 13. Refractory periods for antidromic stimulation and blocking by a direct spike. Stimslation over the urohypophysis $1.5 \mathrm{~mm}$ caudal to the recording site and through the microelectrode. The minimum interval at which an antidromic response could invade the soma following a previous spike was quite long, and in none of the records did antidromic invasion occur during a second response, only the axonal component being seen. A: Superimposed traces showing the two latencies obtained on antidromic stimulation. B: The refractory period for a pair of equal stimuli, the first of which evoked a short latency response (superimposed traces where second response did and did not occur). Before failure the second response showed a slight increase in latency. $\mathrm{C}$ : The same stimuli at the same interval as in $\mathbf{B}$. Sometimes the sccond response had the long instead of the short latency (superimposed traces as in B). D: A spike directly evoked in the soma blocked the short latency antidromic response at close to the interval, indicated by the dotted line, equal to the refractory period for the paired antidromic stimuli plus the antidromic conduction time (superimposed traces where the antidromic response was and was not blocked). $\mathrm{E}$ : The response to a pair of equal stimuli, the first giving a long latency response. The response to the second stimulus occurred at the short latency. F: At a slightly shorter interval than in E the latency of the second response returned to near the long value. $G$ : At a still shorter interval than in $F$ the second response failed, but with little preceding increase in latency (superimposed traces as in B). The refractory period was only slightly greater than in B. H: A spike evoked directly in the soma blocked the long latency antidromic response at close to the interval, indicated by the dotted line, equal to the refractory period for the paired antidromic stimuli plus the antidromic conduction time (superimposed traces as in D). spread electronically from the soma may block antidromic propagation at these points.

A not uncommon response was like that illustrated in Fig. $14 \mathrm{~A}$ where the large spike component that was blocked by hyperpolarization appeared to arise from the axonal component at a potential below the firing level of the cell (B), even a little below the resting potential. This component, therefore, could not have arisen

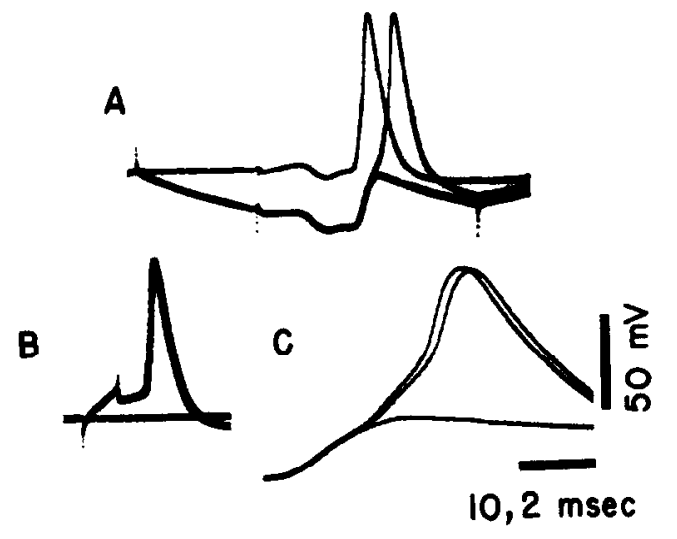

Fis. 14. Block of antidromic invasion just distal to the axon hillock region. Stimulation over the urohypophysis. A: Hyperpolarization adequate to cause occasional failure of a large spike component. This component appeared to arise from the peak of the remaining axonal component at a level below the resting potential. It must therefore have arisen distal to the electrode (superimposed responses with and without hyperpolarization). B: Responses to near threshold direct stimulation. The firing level would have been slightly below the potential immediately following the stimulus (cf. Fig. 10). C: Superimposed records of expanded sweeps with hyperpolarization as in $\mathrm{A}$. There was an inflection on the rising phase of the component that failed, presumably due to delay in the axon hillock region, block occurring at a more distal point.

right at the electrode, but must have been initiated a short distance away where the depolarization produced by the invading impulse was greater. It had an additional inflection on its rising phase $(\mathrm{C})$, which probably resulted from delay at the axon hillock, the block occurring at a more distal point. This result is not dissimilar to the 
finding in some motoneurons of the cat that with increasing hyperpolarization or refractoriness the initial segment may fail to be excited by the first node before invasion of the soma fails (Fuortes et al., 1957).

With increase in hyperpolarization beyond that adequate to prevent invasion of the cell body, a level was often reached where a further slight increase in polarization caused a virtually complete block of the remaining axonal component. This block usually required less hyperpolarization with responses of longer latency in spite of their being initiated farther from the soma, where the hyperpolarization was being applied (Fig. 15). However, the block appeared to result not from preventing the initiation of the longer latency responses, but rather of preventing their propagation across some more proximal

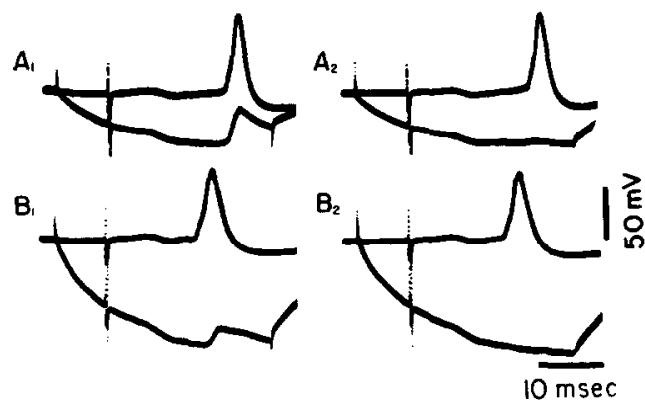

FIG. 15. Block of the axonal component of antidromic responses with different latencies. Stimulation over the urohypophysis $5 \mathrm{~mm}$ caudal to the recording site. Superimposed traces in each case with and without hyperpolarization. $A_{1}$ : The hyperpolarization was more than adequate to block invasion of the soma by the long latency response to a weak antidromic stimulus. The axonal component remained. $A_{2}$ : A slight increase in hyperpolarization blocked or at least greatly reduecd the axonal component. $\mathrm{B}_{\mathrm{I}}$ : The shorter latency axonal component in response to a stronger antidromic stimulus was not blocked by a larger hyperpolarization although, since it was reduced in height over that in $A_{1}$, it probably did not invade as far. It was also somewhat delaved but the delay had developed in a graded fashion suggesting reduced conduction velocity due to the hyperpolarization that had electronically spread out the axon. $\mathrm{B}_{2}$ : A slight increase in hyperpolarization again blocked the axonal component. point in the axon. The stronger stimuli cither facilitated conduction across this point or initiated impulses still more proximally. Evidence for block of a long latency response proximal to its site of initiation is shown in Fig. 16. Hyperpolarization did not block the axonal component completely; only a small potential remained, however, indicating that the block was far from the soma (F). A slight shortening of the pulse that in $B$ was adequate to block the response allowed invasion

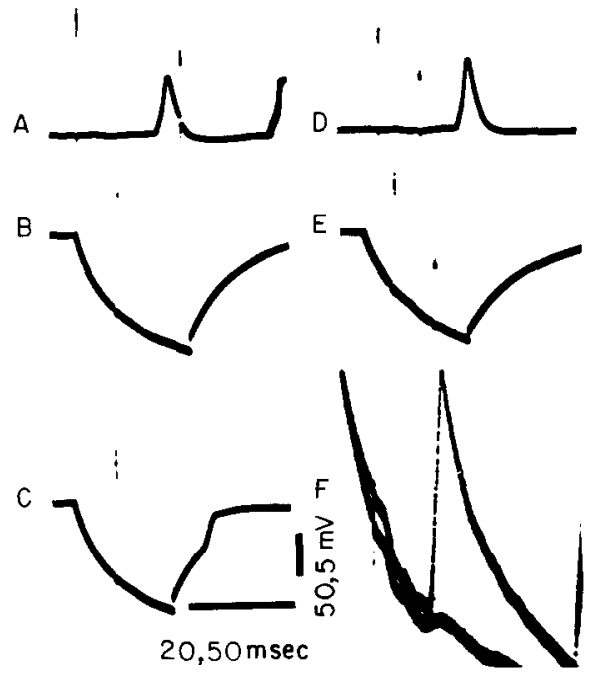

Fia. 16. Block of antidromic propagation along the axon distant from the soma. Stimulation over the urohypophysis $2 \mathrm{~mm}$ caudal to the recording site. A : A pair of weak stimuli each producing a long latency antidromic response. B: The response to the first stimulus alone was virtually completely blocked by a hyperpolarizing pulse. C: Slight shortening of the pulse allowed the axonal component of the spike to occur, although up to a time more than 10 msec following the stimulus to the urohypophysis the hyperpolarization was unchanged compared with that in B. D: The pair of stimuli given in $A$ at a closer interval. The second response failed. E: Hyperpolarization adequate to block the first response did not allow a response to occur to the second stimulus, although the hyperpolarization did not block the response to this stimulus alone (cf. C). F : Increased gain and reduced sweep speed with hyperpolarization adequate to cause occasional failure of the axonal component. A small potential remained when the large axonal component failed (two superimposed traces). 
nearer the soma (C), although the hyperpolarization was unchanged at the time of antidromic stimulation and for more than 10 msec afterwards. Block of the response did not prevent refractoriness to a second stimulus which by itself would have resulted in at least the axonal component of the spike (D; cf. C).

On several occasions the antidromic responses were observed to show a stepwise increase in latency when the soma was hyperpolarized. This result was probably due to block of the shorter latency response near its site of initiation without block of conduction of the more distantly initiated impulse. The smaller (graded) increases in latency that were observed (cf. Fig. 15B ${ }_{1}$ ) would have been due to reduced conduction velocity as a result of the hyperpolarization electronically spread into the axon. The hyperpolarization would also have effected the gradual reduction in amplitude of the axonal response by a gradual decrease in the limit of invasion (ef. Fuortes et al., 1957).

Responses in the Neurosecretory Cell Axons. Spikes ascribable to the neurosecretory axons were rather smaller and more diverse in form than those in the cell bodies. They were usually about the same duration as soma responses but lacked undershoots. In view of the small axonal diameter, they were recorded with surprising frequency and injury was no doubt common. The responses of fibers were characterized in either of two ways as in the skate. In the experiment of Figs. 17A$17 \mathrm{C}$ the spikes that were elicited by rostral stimulation could be identified as synaptically evoked by their long and variable latency which contrasted with the shorter and constant latency of the tract response simultaneously recorded by the same electrode. No p.s.p.'s were observed, however. In Fig. 18 spikes identified as directly evoked by their short or constant latency were obtained from both rostral and caudal stimulation.

The neurosecretory axons constitute the largest fiber component in the posterior cord, and all the more posteriorly recorded responses in fibers appeared to be in those

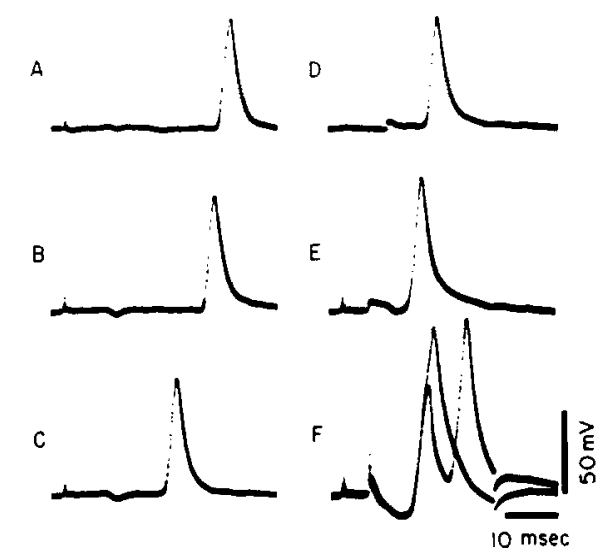

FIG. 17. Synaptically evoked and antidromic spikes in a neurosecretory axon. A-C: Spikes in response to increasing stimuli given $7 \mathrm{~mm}$ rostral became of much shorter latency and must therefore have been synaptically evoked. No ps.p. was recorded, however, indicating that the elec:trode was in a fiber. The tract response due to direct stimulation of some other neurosecretory axons could be seen preceding the spike. This earlier potential had a constant latency of about 10 msec, although it increased somewhat in size indicating stimulation of additional axons. D: A long latency response to stimulation over the urohypophysis $1 \mathrm{~mm}$ caudal to the recording site. The minimum antidromic latency was about $1 \mathrm{msec}$. $\mathrm{E}$ : The response to stimulation as in $\mathrm{D}$ blocked the synaptic spike evoked by stimulation as in C. $\mathrm{F}$ : The same stimuli as in $\mathrm{E}$, hyperpolarization could cause a second component of the first response to fail. When this component failed, the synaptic spike reappeared (superimposed traces with and without the second component). The first response must therefore have arisen on the opposite side of the recording electrode from the synaptically croked response, and been antidromic in origin.

of the neurosecretory cells. As well as being of similar duration to the soma spikes, they had appropriate conduction velocities and patterns of response to rostral and caudal stimulation. Brief, rapidly conducting spikes characteristic of myelinated fibers could be recorded from ventral roots, but were not found in the cord posterior to the third vertebrum rostrally.

As in the case of myelinated fibers (cf. Fig. 4), conduction along the neurosecretory axons could be blocked by hyperpolarization, the spike then demonstrating 


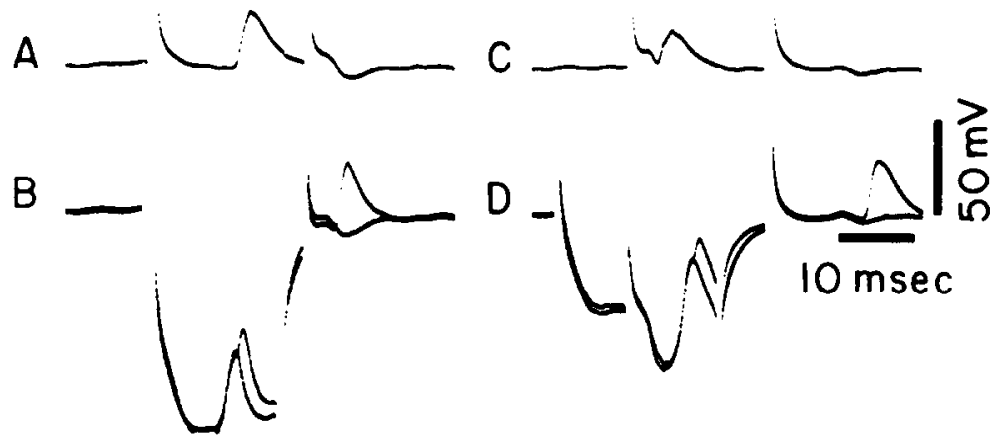

FIG. 18. Directly evoked orthodromic and antidromic spikes in a neurosecretory axon. Stimulation $6 \mathrm{~mm}$ rostral to the recording sitc and $2 \mathrm{~mm}$ caudal which was over the urohypophysis. $\Lambda$ : The rostral stimulus preceded the caudal. The fiber was refractory to the second stimulus. The response to rostral stimulation was identified as direct because there was little change in latency with stimulus strength, and the latency was short compared to the usual synaptically evoked responses. The latency was close to that of the tract response to the stimulus which can be seen in C and D (order of stimulation reversed). B: Hyperpolarization could cause a second component of the rostral response to fail. When this component failed, a response to the caudal stimulus occurred indicating that propagation across the recording site had been blocked (superimposed traces with and without the second component). $\mathrm{C}$ and $\mathrm{D}$ : $\mathrm{As}$ in $\mathrm{A}$ and $\mathrm{B}$, but with order of stimulation reversed. The response to caudal stimulation must have been direct because of its short latency.

two components. In Fig. 18 the response to each stimulus left the fiber refractory to a following stimulus on the other side of the recording site $(\mathrm{A}, \mathrm{C})$. When hyperpolarization was applied adequate to block the second component of the earlier response, the ensuing stimulus was able to evoke a spike $(B, D)$.

The block of conduction along a fiber could sometimes be used to determine the direction in which an impulse was traveling. In Fig. 17 the synaptically evoked spike (C) was blocked when preceded (E) by a long latency response to stimulation over the urohypophysis (D). The response to the caudal stimulus could not be determined to be antidromic by the site of stimulation alone (cf. Fig. 20), and its latency was consistent with either synaptic or antidromic origin. Howcver, when its propagation was prevented by hyperpolarization as denoted by failure of its second component (F) it no longer blocked the synaptic response. It must therefore have arisen on the opposite side of the recording site from where the synaptic spike arose, and have been antidromic in origin.

Properties of the Presynaptic Fibers. Stimulation of the cord five segments rostral to the urohypophysis, which was well be- yond the neurosecretory cells, still evoked a p.s.p. in them (Fig. 19C), suggesting that the presynaptic pathway descended from an anterior part of the nervous system. An approximate value for the conduction velocity in the pathway could be obtained by stimulating at two sites a measured distance apart and determining the difference in latency of the p.s.p.'s. This value, 4.5 $\mathrm{m} / \mathrm{sec}$ for the experiment of Fig. 19 and

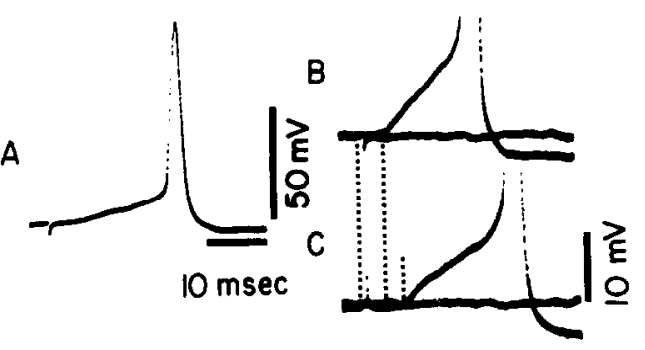

FIG. 19. Conduction velocity in the presynaptic pathway. A: Synaptically evoked spike from stimulation $11 \mathrm{~mm}$ rostral to recording site. B: Same site of stimulation, recording at higher gain to show the latency of the p.s.p. C: Stimulation $24 \mathrm{~mm}$ rostrally which was five segments rostral to the urohypophysis, recording at the higher gain. The latency was increased by an amount corresponding to a presynaptic conduction velocity of $4.5 \mathrm{~m} / \mathrm{sec}$. 
up to $10 \mathrm{~m} / \mathrm{sec}$ in other experiments, represents the relocity in the most rapidly conducting elements. The irregularities that could occur during the p.s.p.'s (ef. Fig. 9) might have been due to contributions from later arriving impulses.

Many, if not all, of the axons which ended on the morc rostral cells ran farther caudally, probably also ending on the more caudal cells. This aspect of the innervation is shown by the interaction of p.s.p.'s which could be evoked by stimuli both caudal and rostral to a given cell (Fig. 20). At short intervals whichever postsyn- arrows. These small potentials were presumably due to tonic actirity in one or a few presynaptic fibers. Intravenous injection of distilled water caused a great increase in the synaptic activity, resulting in irregular firing ( $\mathrm{B}, 1.5$ minutes after injection of 4 ce distilled water). The increase in p.s.p.'s was particularly obvious when the ecll was hyperpolarized sufficiently to prevent firing (D). The intervals between spikes were quite irregular $(\mathrm{B}, \mathrm{C}, \mathrm{E}, \mathrm{F})$ as distinct from the highly uniform discharge in response to injury.

The threshold blood dilution for the re-
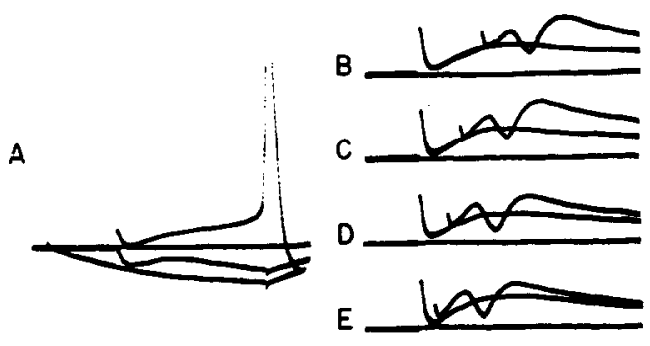

FIG. 20. Interaction of p.s.p.s from rostral and caudal stimulation. A: Response to stimulation $2.5 \mathrm{~mm}$ rostral to the recording site. Superimposed traces showing a synaptically evoked spike and its block by hyperpolarization revealing the early peak of the p.s.p. B-I: In addition to the rostral stimulus, one was given over the urohypophysis $3.5 \mathrm{~mm}$ caudal to the recording site. This stimulus resulted in a p.s.p. which was superimposed on the tract response of the neurosecretory axons. A constant hyperpolarizing current was passed to block impulse generation. Superimposed traces show baseline, first stimulus alone, and first and second stimuli together. In B-F the rostral stimulus preceded the caudal; in G-I the stimuli were in the opposite order. At the longer stimulus intervals the p.s.p.'s summed. At the shorter intervals the second p.s.p. was greatly reduced. In $F$ only the triphasic tract response appeared to occur in response to the caudal stimulus.

aptic potential was second was greatly reduced ( $F, G)$. However, when the interval between stimuli was greater than about 5 msec the p.s.p.'s summed without significant reduction in amplitude of the second ( B, C, I; note the triphasic tract response superimposed on the p.s.p. due to caudal stimulation).

The physiological role of the caudal neurosecretory cells remains somewhat obscure, but is apparently involved in osmoregulation (Enami, 1959; Bern and Takasugi, 1962). In many cells there were seen at high gain small potentials close to the noise level, but nevertheless in duration of the same order as the p.s.p.'s (Fig. 21, sponse has not as yet been determined. Assuming 5\% blood volume, the average dilution in the experiment of Fig. 21 was about $10 \%$, but the rate of mixing with the blood and with other body fluids is problematical. Injections of hypertonic $\mathrm{NaCl}$ solutions had no effect, at least on quiescent cells.

\section{DISCUSSION}

The caudal neurosecretory cells in the fluke have definitely been found capable of producing action potentials and of being: synaptically activated. With somewhat less reliability because of their anatomical situation the caudal neurosecretory cells of 
the skate can be said to have similar properties. In the fluke impulses were initiated by the injection of hypotonic solutions, apparently physiologically through increased activity of the presynaptic fibers. The impulses would have been propagated to the region of the terminals, but direct evidence that the cells' electrical activity resulted in secretion of neurohormone was not obtained.

The origin of the presynaptic fibers is unknown, but since they lie anteriorly in both fluke and eel (Morita et al., 1961), an

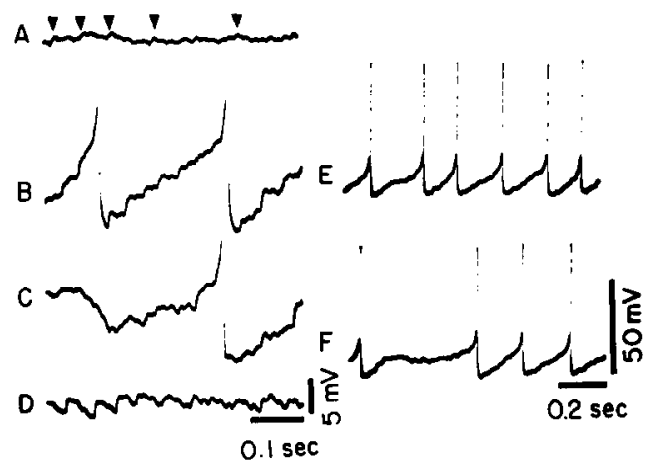

FIG. 21. Activation by hypotonic solutions. A: Spontaneous activity (arrows), presumably p.s.p.'s resulting from activity in one or a few presynaptic fibers. Following this recording $4 \mathrm{cc}$ of distilled water was injected into the vein ventral to the spinal column about $8 \mathrm{~cm}$ rostral to the urohypophysis. B, C: 1.5 minutes later there was a great increase in synaptic activity, and the cell began to fire. D: The increased frequency of synaptic activity was clearly apparent when the cell was hyperpolarized sufficiently to block firing. E, F: Recorded at lower gain and sweep speed to show the irregular frequency of firing.

encephalic center might be expected. This center would be activated by enteroreceptors for the physiological stimulus and, indeed, might contain or consist of them. The question of interneurons in the descending pathway is also not resolved. The presynaptic conduction velocity in the nuke was sufficiently rapid to suggest small myelinated fibers, and the results shown in Fig. 20 are consistent with monosynaptic activation of the neurosecretory cells. No intracellular recordings were obtained in the posterior cord that could be ascribed to the presynaptic fibers.

A number of obvious controls on the presumed physiological activation by hypotonic solutions have yet to be performed. If there is an encephalic control center a rostral spinal section should block the response, and sensitivity to locally applied solutions should be absent. Generalized neuronal activation should also not occur. It is already clear from the great increase in synaptic activity that the response was at least primarily mediated by presynaptic fibers rather than by direct sensitivity of the neurosecretory cells themselves (Fig. 21). In addition the absence of antidromic firing (Fig. 21D) demonstrates that the neurosecretory axons were not particularly sensitive to the hypotonic stimulus.

The precise nature of the stimulus has also to be determined. It is not clear whether activation resulted from reduction in osmotic pressure or in the concentration of any specific blood constituent. Activation by hypotonic solutions is the opposite from that which would be predicted from the results of Bern and Takasugi (1962). These workers compared normal and urohypophysectomized individuals of a fresh water species on immersion in hypertonic solutions. The operated animals showed greater mortality, weight loss, and increase in blood chloride concentration. Apparently in this form the hormone tends to maintain or decrease blood concentration against an abnormal inward concentration gradient. A decrease in permeability or increase in active transport would be required. In the fluke the hormone presumably tends to increase blood concentration in the normal, marine environment. which is down a concentration gradient. This effect could result simply from increased permeability leading to increased passive movement.

The electrophysiological properties of the neurosecretory cells are well adapted to tonic activation which is probably the normal mode. There is very little accommodation as indicated by the long latencies to brief stimuli (Figs. 5, 10), and by the prolonged low frequency injury discharges 
that were often observed. One specialization that occure in motoneurons, that of having a low threshold initial segment region, was not found in the neurosecretory cells, at least those of the fluke (Figs. 9, 10). The proposed function in motoneurons of this property, to assure averaging of somatic and dendritic p.s.p.'s (Coombs et al., 1957), would not be important, however, since the dendrites of the neurosecretory cells are quite short and the synaptic input probably all of one type. The failure to observe antidromic spikes in the skate neurosecretory cclls may have been a result of the shortness of the axons as well as of there being no great difference in excitability between axon and soma.

The low safety factor points for antidromic propagation along the axon do not: have an obvious anatomical basis. One such point might have occurred at the junction between urohypophysis and spinal cord where there is a marked cytological and, perhaps, electrophysiological differentiation. Ilowever, little hyperpolarization could have reached this point from the cell bodies of the more rostral cells in which the axonal block of propagation was obtained (cf. Fig. 15). The safety factor along the axon could be reduced, like at the axon hillock, by an enlargement of the membrane such as due to branching or an accumulation of secretory product. On the other hand, the secretory product might increase the axoplasmic resistance. An accumulation could then hinder local circuit propagation by reducing the intracellular longitudinal action current. This result would be analogous to the slowing or block of propagation in a nerve fiber that can be produced by increasing the resistance for flow of external current (Hodgkin, 1939; Tasaki and Frank, 1955).

As yet no significance can be attached to the rather long duration of the ncurosecretory action potentials or to the extremely low conduction velocity in or near the terminals. These properties might cause the secretion due to a single impulse to last longer. Probably secretion considerably longer than the transmitler release in ordinary nourons would be desirable in view of the low firing frequency of the cells (Fig. 21; ef. Eecles, 1957). Even at the estimated conduction velocity in the terminals, impulses could propagate the entire length of the animal in a matter of seconds so that the slowness would not introduce delays significant for an osmoregulatory function. The electrical activity of the terminals certainly requires further study. Thus far in the fluke, no more than very small externally recorded spikes have been obtained from the urohypophysis itself. It might be more practical to obtain intracellular recording from the terminals in a species where they are relatively large (cf. Bern and Takasugi, 1962).

\section{ACKNOWLEDGMENTS}

Prof. Bennett holds a Research Career Development Award from the Cinited States Public Health Service. The work was supported in part by grants to Prof. H. Grundiest from the Muscular Dystrophy Associations of America, Inc., National Institute of Neurological Diseases and Blindncss (B-389 C5 and C6), National Science Foundation (NSF G-5665) and United Cerebral Palsy Research and Educational Foundation and to the Marine Biological Taboratory under its contract with the Office of Naval Research.

\section{REFERENCES}

Araki, T., and Otani, T. (1955). Response of single motoneurons to direct stimulation in toad's spinal cord. $J$. Neurophysiol. 18, 472-485.

Bers, H. A. (1962). The properties of neurosecretory cells. In "Proceedings Third International Symposium on Comparative Endocrinology." Gen. Comp. Endocrinol. Suppl. 1, 117-132.

Bern, H. A., axd Takasugi, N. (1962). The caudal neurosecretory system of fishes. Gen. Comp. Endocrinol. 2, 96-110.

Cooke, I. (1962). Effects of the pericardial neurosecretory substance on the crustacean heart. Gen. Comp. Endocrinol. 2, 29.

Coombs, J. S., Curtis, D. R., axd Eccles, J. C. (1957). The generation of impulses in motoneurons. J. Physiol. 139, 232-249.

Cross, B. A., And Green, J. D. (1959). Activity of single neurons in the hypothalmus: effect of osmotic and other stimuli. J. Physiol. 148, 554-569.

Eccles, J. C. (1957). "The Physiology of Nerve Cells." 270 pp. Johns Hopkins Press, Baltimore, Maryland. 
Enami, M. (1959). The morphology and functional significance of the caudal neurosecretory system of fishes. In "Comparative Endocrinology" (A. Gorbman, ed.), pp. 697-724. Wiley, New York.

Frank, K., and Fuortes, M. G. F. (1955). Potentials recorded from the spinal cord with microelectrodes. J. Physiol. 130, 625-654.

Fuortes, M. G. F., Frank, K., and Becker, M. C. (1957). Steps in the production of motoneuron spikes. J. Gen. Physiol. 40, 735-752.

GrundFest, H. (1959). Synaptic and ephaptic transmission. In "Handbook of Physiology, Neurophysiology I" (J. Field, ed.), pp. 147197. American Physiological Society, Washington, D. C.

HaRrIs, G. W. (1947). The innervation and actions of the neurohypophysis; an investigation using the method of remote control stimulation. Phil. Trans. Roy. Soc. London, Ser. B, 232, 385-441.

HodgKin, A. L. (1939). The relation between conduction velocity and the electrical resistiv- ity outside a nerve fibre. J. Physiol. 94, 560 570 .

Morita, H., Ishibashi, T., and Yamashita, S. (1961). Synaptic transmission in neurosecretory cells. Nature 191, 183.

Potter, D. D., and Loewenstein, W. R. (1955). Electrical activity of neurosecretory cells. $\mathrm{Am}$. J. Physiol. 183, 652.

Speidel, C. C. (1919). Gland cells of internal secretion in the spinal cord of the skates. Publ. \#271, Carnegie Institute of Washington.

SPEIDEL, C. C. (1922). Further comparative studies in other fishes of cells that are homologous to the large irregular glandular cells in the spinal cord of the skates. J. Comp. Neurol. 34, 303-312.

TasakI, I. (1952). Properties of myelinated fiber in frog sciatic nerve and in spinal cord as examined with microelectrodes. Japan J. Physiol. 3, 73-94.

Tasaki, I., and Frank, K. (1955). Measurement of the action potential of myelinated nerve fiber. Am. J. Physiol. 182, 572-578. 